\title{
The Impact of Environmental Factors on Malaria Prevalence in A Peri-Urban Community
}

\author{
Olubunmi A Mokuolu ${ }^{1}$, Oluwayemisi D Adegboye ${ }^{2}$, Olugbenga A Mokuolu ${ }^{3}$ \\ ${ }^{1}$ Environmenal Unit, University of Ilorin Teaching Hospital, Ilorin, Kwara state, Nigeria. \\ ${ }^{2}$ DMST, Ministry of Health, Ilorin, Kwara State, Nigeria. \\ ${ }^{3}$ Department of Paediatrics and Child Health, University of Ilorin, Ilorin, Kwara state, Nigeria.
}

\begin{tabular}{l} 
Article Info \\
\hline Article history: \\
Received Jun 07, 2014 \\
Revised Jul 20, 2014 \\
Accepted Aug 24, 2014
\end{tabular}

\section{Keyword:}

Environment

Malaria

Open drainage

Solid waste

Stagnant water

\begin{abstract}
There is a consensus on the relationship between Malaria Prevalence (MP) and Environmental Factors (EF); however, there is a dearth of published data providing this evidence in a quantifiable way. This community based study was undertaken to identify the magnitude of the relationship between MP and key environmental factors in Okelele, Ilorin East Local Government Area of Kwara State, Nigeria. A multi-staged sampling procedure was adopted for the selection of 501 children from 200 households. Children under the age of 14 years in the selected households were sampled to obtain baseline MP using malaria Rapid Diagnostic Test (mRDT) kit. Key household informant interviews and structured questionnaire were used. Relevant sociodemographic characteristics of the households, EF and non EF were determined. Acquired data was analyzed using statistical tools to determine the relationship between various independent variables and mRDT. Variables were also entered into a multiple regression equation for the generation of a mathematical model. Ethical consent was obtained from the parents before samples were taken. The study showed that EF contributed to MP in the study area. Integrated waste management system, and regular environmental sanitation were recommended.
\end{abstract}

Copyright (c) 2014 Institute of Advanced Engineering and Science. All rights reserved.

\section{Corresponding Author:}

Olubunmi A Mokuolu, Environmental Unit, University of Ilorin Teaching Hospital, Ilorin, Kwara State, Nigeria.

Email: olubunmimokuolu@yahoo.com

\section{INTRODUCTION}

Malaria is a serious problem in Africa where one in every five $(20 \%)$ childhood deaths is due to the effects of the disease [1]. There were an estimated 216 million episodes of malaria in 2010, of which approximately $81 \%$, or 174 million cases, were in the African Region. There were an estimated 655000 malaria deaths in 2010, of which $91 \%$ were in Africa. Approximately $86 \%$ of malaria deaths globally were of children under 5 years of age [2]. Two hundred and fifty million malaria cases are reported every year with about $1,000,000$ deaths [3]. It is reported that every $30 \mathrm{secs}$, a child dies from malaria. About 3.3billion people (half of the world's population) are at risk of malaria [4],[1]. Many children who survive an episode of severe malaria may suffer from learning impairments or brain damage [5].

The control of malaria involves three living being and their environment. These include man, mosquito and the larva. Man is highly mobile and able to facilitate the spread of the disease far and wide. Mosquitoes are moving, highly adaptable and have shown resistance to some insecticides [6]. Eggs and larvae are highly adaptable to various environmental situations. This interrelationship of the various living being sustaining the burden of malaria can be described as a malaria chain. In the light of this chain, malaria 
control involves measures that are deployed to disrupt the chain in order to reduce malaria burden to a point where it is not of public health importance. Effective malaria control must leverage on the various opportunities to interrupt the critical chain of man, mosquito and larva. So far malaria control efforts has addressed issues related to man as host (use of drugs for disease prevention and treatment), mosquitoes (use of insecticides) The environmental dimensions as regarding larval reduction is also through larviciding is not very prominent in discussions on malaria control. In addition the impact of environmental factors, while generally acknowledged, is not properly quantified and demonstrated through hard evidence. The absence of such evidence may have weakened advocacy that could enable policy makers to appreciate the direct relationship between the environment and malaria disease burden.

\section{Objectives:}

Baseline malaria prevalence in the study site was determined, environmental problems (drainages, stagnant waters, and solid waste management) that predispose to mosquito breeding and habitation were determined, a mathematical model for the relationship and relative contribution of the environmental factors to malaria burden in Okelele community was developed.

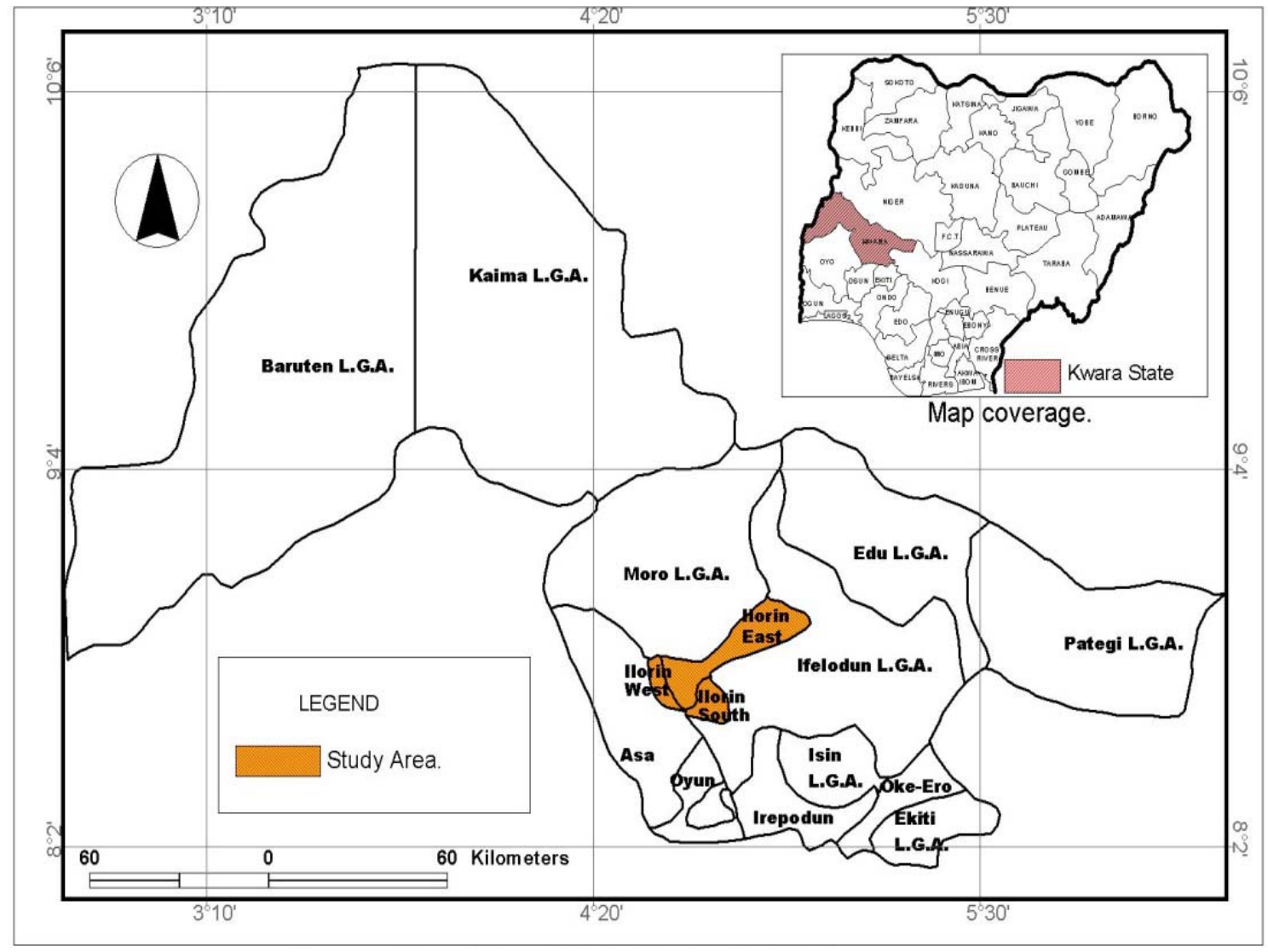

Figure 1. Map of Kwara state showing the study area insert is map of Nigeria (adapted from Tunde et al, 2013)

\section{RESEARCH METHOD}

The study was conducted in Okelele in Ilorin East local Government area of Kwara State, Nigeria. Okelele has a population of 36,191 based on 2006 census. It has a rural setting and lies between longitude $04^{\circ}$ $32^{\prime}$ and latitude $08^{\circ} 26^{\prime}$ with estimated land area of $1.5 \mathrm{Km}^{2}$. Ilorin is the capital of Kwara State with 16 local Government areas, it is located within Longitudes $4^{\circ} 30^{\prime}$ and $4^{\circ} 45^{\prime} \mathrm{E}$ and Latitudes $8^{\circ} 25^{\prime}$ and $8^{\circ} 40^{\prime} \mathrm{N}$, covering a land area of $75 \mathrm{Km}^{2}$. A preliminary survey of the study site was conducted identifying the presence of environmental factors that could contribute to malaria burden of the area. This survey was focused on the presence of drainages, types of wastes in the drainages, and socio-demographic status of the 
population in the study area. A minimum sample size of 422 was obtained from the formula $\mathrm{n}=\mathrm{z}^{2} \mathrm{p}(1-\mathrm{p}) \div \mathrm{d}^{2}[7]$.

A multi-staged sampling procedure was thereafter adopted for the purpose of the conduct of the household survey. Okelele area was divided into 5 zones based the assistance of a local guide namely, Lowin, Amuyankan, Omoboriowo, Jagun, and Baba Ladifa. From each of the zones, 40 households were randomly selected through the help of the local guide. Key household informant interview, using structured questionnaire was conducted to collate information on household characteristics. Relevant sociodemographic characteristics of the households and environmental factors such as Presence of Open Drains (POD), Solid Waste in Drains (SWD), Presence of Weeds (POW) around the house, STagnation of Wastewater in Drains (STWD) were considered. Non environmental factors such as EDucational Level of household heads (EDL), Availability of Mosquito Nets (AMN), Opening of Windows at Night (OWN), use of Insecticide Treated Nets (ITN) were also determined. Variables were entered into a multiple regression equation for the generation of a mathematical model using Stata 8.0 2003 Special Edition (Stata Corporation; College Station, Texas, USA), to determine the relationship between various independent variables and $\mathrm{mRDT}$. Malaria prevalence was determined in children under 14years; representing the most vulnerable age group to the disease. This was to eliminate the possible bias from a type-2 error that may arise from under representation of adult subjects. Blood samples were collected from finger pricks of subjects by a certified medical officer and tested using the mRDT kit. Structured questionnaires were administered and the response rate was $100 \%$.

\section{RESULTS AND ANALYSIS}

The following predictors: Solid Wastes in Drains (SWD), Stagnation of Wastewater in Drains (STWD), Presence of Open Drains (POD), and Presence of Weeds (POW) having p-value $<0.05$ level of significance contributes significantly as independent variables in explaining the dependent variable, malaria prevalence (using mRDT).

Malaria has been known to be a deadly disease from time immemorial and a major public health problem. There are 106 endemic countries of which Nigeria is one [2].The findings of this research have shown that environmental factors play a major role in contributing to the disease.

The average age of the children examined was 6.2 years, mean weight was $19.1 \mathrm{~kg}$, and mean temperature was $36.5^{\circ} \mathrm{C}$. There were 241 females and 260 (Table 1) males which shows almost equal representations of both sexes in the total subjects.

Table 1. Baseline characteristics of study population

\begin{tabular}{ccc}
\hline Characteristics (Sex) & Frequency & Percent \\
\hline Female & 241 & 48.1 \\
Male & 260 & 51.9 \\
\hline Total & 501 & 100 \\
\hline
\end{tabular}

Table 2. Malaria Prevalence with use of mRDT

\begin{tabular}{ccc}
\hline & Frequency & Percent \\
\hline Positive & 150 & 29.9 \\
Negative & 351 & 70.1 \\
\hline Total & 501 & 100 \\
\hline
\end{tabular}

From the mathematical model (Tables 3 and 4) the predictors: Household Types (HHT), Availability of Drains (AVD), Presence of Open Drains (POD), Solid Wastes in Drains (SWD), Availability of Door Net (AVDN), use of insecticide treated net (ITN), Presence Of Weeds (POW) around the house and EDucational Level of household heads (EDL) has a negative regression coefficient ( $\alpha$-value), which shows a negative regression relation with RDT, an indicator of malaria prevalence. Stagnation of Wastewater in Drains (STWD) has the highest $\beta$-value (0.4292), showing that the predictor makes the strongest unique contribution to explaining the dependent variable when the variance explained by all other variables in the model is controlled for. Presence of Weeds (POW) with $\beta$-value $(-0.3423)$ made the least contribution in explaining malaria prevalence as indicated by mRDT. 
Table 3. Table of coefficients for predictors of malaria prevalence

\begin{tabular}{lccccc}
\hline Model & $\boldsymbol{\alpha}$ (coefficient) & Std. Error & $\boldsymbol{\beta}$ & t-value & Sig. (p-value) \\
\hline HHT & -0.3008 & 2.5020 & -0.0063 & -0.12 & 0.904 \\
AVD & -3.8564 & 7.7496 & -0.0448 & -0.50 & 0.619 \\
NUMD & 3.2619 & 7.4892 & 0.0373 & 0.44 & 0.664 \\
POD & -19.7046 & 4.2200 & -0.2569 & -4.67 & 0.000 \\
SWD & -14.5096 & 5.7069 & -0.1302 & -2.54 & 0.012 \\
STWD & 31.5975 & 4.0264 & 0.4292 & 7.85 & 0.000 \\
AVDN & -8.1945 & 4.8367 & -0.1068 & -1.69 & 0.092 \\
AVWN & 4.1635 & 5.2843 & 0.0498 & 0.79 & 0.432 \\
AMN & 0.1710 & 6.8189 & 0.0021 & 0.03 & 0.980 \\
ITN & -0.9307 & 7.2839 & -0.0104 & -0.13 & 0.898 \\
OWN & 4.6332 & 5.2249 & 0.0475 & 0.89 & 0.376 \\
POW & -27.6002 & 4.3500 & -0.3423 & -6.35 & 0.000 \\
EDL & -1.0876 & 1.7281 & -0.0327 & -0.63 & 0.530 \\
\hline Constant & 86.9497 & 22.0073 & & 3.95 & 0.000 \\
\hline Signifcant & & & &
\end{tabular}

Significant at 5\%level (2-tailed)

Table 4. Summary of model predictor parameters and ANOVA TABLE

\begin{tabular}{ccccc}
\hline & SS & DF & MS & Num. of Obs. $=200$ \\
\hline Model & 143618.805 & 13 & 11047.6004 & Prob. $>$ F $=0.0000$ \\
Residual & 118544.315 & 186 & 637.335026 & R-square $=0.5478$ \\
Total & 262163.12 & 199 & 1317.40261 & Root MSE $=25.245$ \\
\hline
\end{tabular}

The following predictors: Solid Wastes in Drains (SWD), Stagnation of Wastewater in Drains (STWD), Presence of Open Drains (POD), and Presence of Weeds (POW) having p-value $<0.05$ level of significance contributes significantly as independent variables in explaining the dependent variable.

The value of R-square (0.5478), which is the coefficient of determination shows that $54.8 \%$ of the variation in malaria prevalence as indicated by mRDT is explained by the model while the remaining $45.2 \%$ is due to the random effect of all the other data.

For the probability value for F-test statistic (0.0000) is less than (0.05) level of significance, therefore, the fitted model is significant.

\section{CONCLUSION}

The baseline malaria prevalence (indicated by $\mathrm{mRDT}$ ) is high, $29.9 \%$. This is further explained by the mathematical model revealing Stagnation of water $(p=0.000)$, Solid waste content in drain $(p=0.012)$, Opened drains $(p=0.000)$ and Presence of weeds around the house $(p=0.000)$ as independent significant factors.

The following are the recommendations:

a. Government to ensure integrated solid waste management in the study site, with further communication with the community for cooperation and understanding of the issue at stake.

b. Regular environmental sanitation: sweeping and packing solid waste into appropriate containers,

c. Construction of sustainable public toilets (human excreta were found in the open drains as some houses do not have toilets) in the community.

d. Punishments for defaulters or non compliance with laid down rules.

\section{REFERENCES}

[1] Sachs J, Malaney P, “The economic and social burden of malaria”, nNature, vol. 415, pp. 680-685, 2002. PubMed Abstract.

[2] WHO, "World Malaria Report", 2011.

[3] USAID, "Integrated Vector Management programmes for Malaria control-Programmatic Environmental assessment. January 2007”, USAID prepared by RTI International, 2007.

[4] Gianotti R., "The potential for environmental management to contribute to malaria vector control in western Niger", Massachusetts Institute of Technology Dept. of civil and environmental engineering, pp. 88-93, 2008.

[5] WHO, "The World Health Report", World Health Organization, Geneva, 1997.

[6] Najera J A, Zaim M, "Malaria vector control", World Health Organization communicable disease control, prevention and eradication, 2003.

[7] Wayne W. Daniel, "Biostatistics A Foundation for analysis in the Health Sciences", John Wiley and Sons (Asia) PTE LTD, pp 183-184, 2007. 


\section{BIIOGRAPHIES OF AUTHORS}

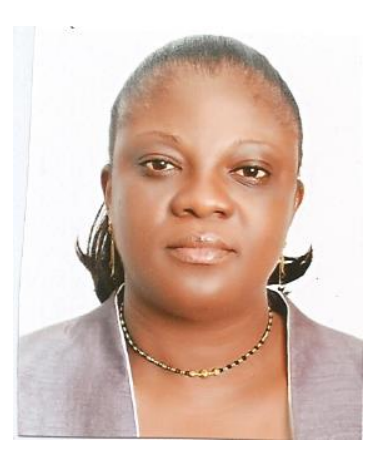

Olubunmi A Mokuolu is a professional Engineer with experience spanning over 15 years in Environmental/ water Engineering, Examiner for professional qualifying exams, master trainer in solid waste management and made publications, holds a bachelor's degree and a masters degree from the University of Ilorin, She is currently at pre-defense level for her $\mathrm{PhD}$ at the University of Ibadan. She has worked in private and public sectors. Olubunmi brought awareness to the unscientific way of handling Health Care Waste at the University of Ilorin Teaching Hospital (UITH). Environmental unit was created through her drive and she was made the pioneer head of the unit. It was to her credit that the UITH developed their first ever Policy on health care waste management. She has, in the course of time as a Master trainer on health care waste conducted several TOTs and regular training for over 900 medical staff of the hospital, cutting across all cadres from the cleaners to the Consultants. She has attended many workshops and conferences as a guest speaker and a participant. Some of which are: Society for Quality in Healthcare in Nigeria, Marking WHO day, Nigerian Society of Engineers, Lagos Medical waste Summit, and Recycling and waste management conference, Birmingham, UK.

Olubunmi is a member of many professional associations some of which are: The Nigerian society of Engineers (NSE), Institution of Civil Engineers (NICE), Association of professional women Engineers (APWEN), and American society of Civil Engineers (ASCE), a chartered Engineer, registered with Council for the regulation of engineering in Nigeria (COREN). She had served as Chairman of committees, former chairperson APWEN in Kwara state and executive committee member of the Nigerian Society of Engineers; She is currently a board member of same association.

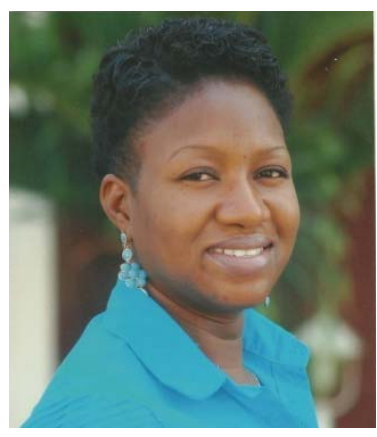

Dr (Mrs) Oluwayemisi Deborah Adegboye is a Medical Officer at the General Hospital Ilorin a secondary health care facility in Kwara State, Nigeria. She has over 5 year's public health experience in the field of Malaria, HIV/AIDS, and Tuberculosis. She also engaged in other public health programs, services and management. She has worked at the federal, state and local government owned hospitals and organizations of which she has great rural public health prospects and understanding. She has also worked with various Non Governmental Organizations of which she presently has an ongoing and award winning program on Adolescent health.

Dr Adegboye has contributed to humanity on the aim of achieving the Millennium Development Goals. She has participated in different types of research and still much interested in many more. Some international researches in which she participated are: African Quinine Versus Artesunate in Severe Malaria Trial, AQUAMAT (2009) and Community Health Plan (CHP) Survey in Kwara Central conducted by Amsterdam Institute for International Development (2013).

Dr Adegboye has worked with many Non Governmental Organizations as consultant; some of which are the Family Health International 360 Nigeria, Institute of Human Virology, Nigeria and Management Sciences for Health, Nigeria. She has also facilitated program for the National Malaria centre, Abuja. Nigeria

She had her MB BS degree (2008) from University of Ilorin, Master of Public Health, MPH (2012) from University of Ilorin and many other certificate courses. 


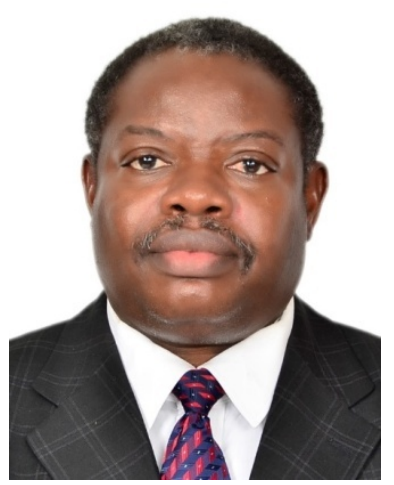

Dr. Olugbenga Mokuolu is a Professor of Paediatrics at the University of Ilorin in Nigeria. He has over 18 years' experience in the care of the newborn in the tropics, malaria case management and diverse public health activities. Dr. Mokuolu earned his medical degree at the University of Ibadan in Nigeria and completed his residency training in paediatrics and neonatology in 1995. He is a fellow of the West-African College of Physicians. His major research focus has been on management of the newborn infections, anthropometry and malaria management; especially gestational age assessment, neonatal infections, perinatal malaria and general care of the newborn with a focus on addressing the challenges of newborn health needs in a developing country using appropriate technology.

Some of Dr. Mokuolu's major contributions have been with respect to use of digitally recycled incubators, pioneering the use of oxygen concentrators as a cost effective means of oxygen delivery in developing countries, and fabrication of radiant warmers. $\mathrm{He}$ has also co-authored a number of landmark publications in the field of malariology. He played major role in the development of the WHO-AFRO and WHOHQ Malaria case management training manuals.

Dr. Mokuolu has served as Chairman for the Medical Advisory Committee at the University of Ilorin Teaching Hospital, acting director of the university's Medical Centre of Excellence, Chairman of the ICT Committee and sub-Dean in the Faculty of Clinical Sciences. He is currently the University's Director Centre for International Education.

Some of Dr Mokuolu's National and International appointments include:

1. May 2012 - Date: Member, National Severe Malaria Treatment Advisory Group

2. May 2009 - Date: Member, Steering Committee on the reduction of maternal, newborn and child mortality in West Africa, West Africa Health Organization

3. May 2004 - Date: Member, Technical Expert Group on Antimalarial Treatment Guidelines World Health Organization. Geneva, Switzerland.

4. May 2007 - Date: Co-Reviewer, Use of Rapid Diagnostic Test in Malaria, WHO Dr Mokuolu is a recipient of many grants/awards for biomedical studies in the field of malaria which include epidemiology of severe malaria, malaria in the peripartum period and antimalarial drug trials. He co-authored a publication on Recycled Incubator Technique (RIT) that ranked as No 1 in the world listing of TOP 50 recent medical findings.

\section{Research Interest}

Use of appropriate technology in the care of the newborn in the tropics and generating evidence to improve management of malaria and conducting antimalarial drug trials. 